\title{
Effort, Satisfaction and Outcomes in Organisations
}

\author{
Marta Posada ${ }^{1}$, Celia Martín-Sierra ${ }^{2}$, Elena Pérez ${ }^{1}$ \\ ${ }^{1}$ Department of Management and Business Organization, School of Industrial Engineering, University of Val- \\ ladolid, Paseo del Cauce 59, 47011 Valladolid, Spain \\ ${ }^{2}$ European Miguel de Cervantes University, Padre Julio Chevalier 2, 47012 Valladolid, Spain \\ Correspondence should be addressed to posada@eii.uva.es \\ Journal of Artificial Societies and Social Simulation 20(2) 9, 2017 \\ Doi: 10.18564/jasss.3418 Url: http://jasss.soc.surrey.ac.uk/20/2/9.html \\ Received: 19-04-2017 Accepted: 07-03-2017 Published: 31-03-2017
}

\begin{abstract}
In this paper, an agent-based model of bounded-rational agents, who adapt both their effort intensity (by the interaction with other employees) and their stay-on-the-job-intention (by the alignment of their personal values with the Human-Resource Management (HRM) practices implemented by the organisation), is proposed. Our aim is to analyse: (i) the emergence of an organisational culture and its relationship with both formal organisational structures and employees' effort-behaviours; (ii) the increase of organisational performance by retaining valuable-performance employees whereas poor-performance employees are dismissed. We have obtained that: (i) Some possible combinations of both employees-effort behaviours and formal organisational structures can favour the emergence of organisational cultures more than others; (ii) The interaction between employees within matrix structures (balanced or strong) with a democratic team leadership favour the emergence of organisational cultures; (iii) High-effort managers are relevant for the emergence of high-performance organisational cultures; (iv) Turnover (voluntary or involuntary) affects the emergence of organisational culture negatively. We conclude that the main challenge is "to retain high effort managers by adapting the set of HRM practices to them".
\end{abstract}

Keywords: Effort, Satisfaction, Performance, Organisational Culture, Human Resource Management Practices, Turnover

\section{Introduction}

1.1 Recently, employees are often considered a source of competitive advantage for organisations. To explain this, Guest 1997) argued that there was a need for (1) a theory on Human Resource Management (HRM), (2) a theory on performance, and (3) a theory on how these aspects are linked. Nevertheless, after reviewing empirical and theoretical research over eight years, Paauwe et al. (2005) observed only modest progress on these three fundamental issues by reviewing empirical and theoretical research over 8 years. In order to drive more longitudinal research, more complex causal models, and multi-level phenomena, Wright et al. (2005) suggested to consider the following concepts (that are often missing in the analyses of the relationship between HRM and performance): time, cause and individuals. Therefore, in order to consider the variance across individuals, we propose to use an agent-based approach to analyse both its cause and effect on the relationship between HRM and performance. Although agent-based modelling may bring opportunities and advantages to management and organisations, management seems to hold back to the agent-based model revolution (Secchi et al.|2015).

1.2 In this paper, we propose an agent-based model (ABM) to link HRM and performance inspired on Guest (1997)'s model within formal organisational structure frameworks (see Figure 17. Our aim is to analyse: (i) the emergence of an organisational culture and its relationship with both formal organisational structures and employees' effort-behaviours; (ii) the increase of organisational performance by retaining valuable-performance employees whereas poor-performance employees are dismissed. 


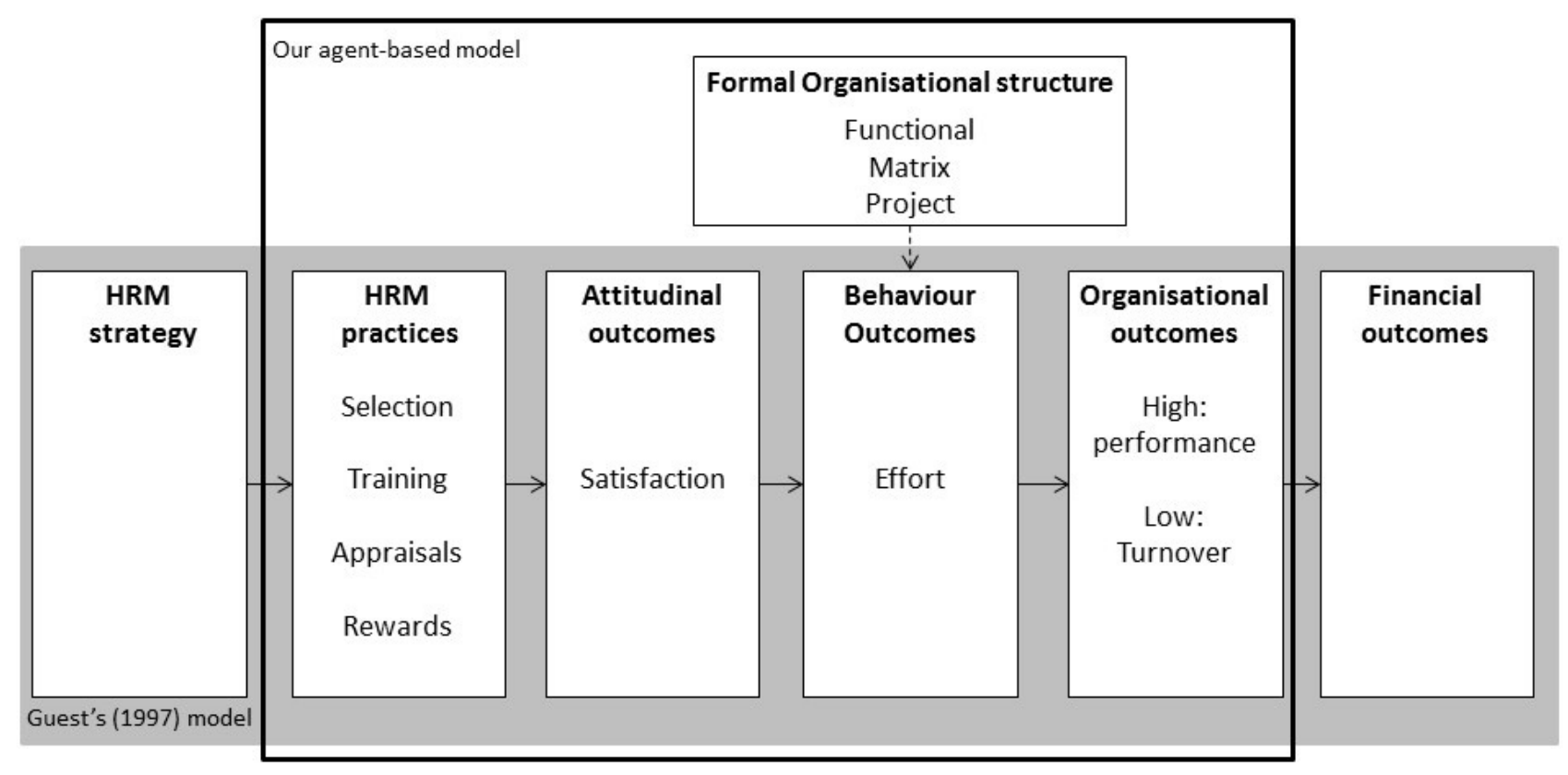

Figure 1: Agent-based model proposed based on Guest (1997)'s model

\section{Organisational structure}

1.3 Organisational structure definitions are as divergent as the approaches to study it. Due to ABMs consist of agents that interact within an environment (Gilbert 2008), our approach is aligned with Dow (1988) who defined organisational structure as "a relatively stable, either planned or spontaneous, pattern of actions and interactions that organisation members undertake for the purpose of achieving the organisation's goals". Therefore, in this paper, the organisational structure dictates the interactions between individuals.

1.4 Organisational structure can be categorised as formal (planned) and informal (spontaneous). In this paper, we focus on formal organisational structure. It ranges from functional to projects, with a variety of matrix structures between them Galbraith 2008. In a functional organisational structure, the employees are grouped into departments (for instance, engineering, manufacturing and, marketing) and functional areas (electrical and mechanical areas in engineering department), whilst in project structures the employees are grouped into teams. In matrix organisational structure (which can be weak, balance or strong) the employees are grouped into both departments and teams. Salas et al. 2005 summarised down what researchers know about teamwork into "big five" components: team leadership, mutual performance monitoring, backup behaviour, adaptability, and team orientation. In this paper, we focus on the team leadership component because it dictates the formal interactions between team members.

\section{Human Resource Management (HRM) practices}

1.5 The HRM practices (such as job design, human resource planning, recruitment and selection, performance appraisal, promotion, work-family balance programs, etc.) enhance organisational performance. Dyer et al. (1995) stated four levels of HRM outcomes: employee, organisational, financial and market, but we limit to the three levels captured by Guest (1997)'s model: financial outcomes (such as profits and return on investment), organisational outcomes (such as productivity and turnover) and employee outcomes. Employee outcomes consist of attitudinal outcomes (such as commitment, job satisfaction and intention to leave) and behavioural outcomes (such as effort, motivation, cooperation and organisational citizenship).

1.6 In order to model the black boxes of Guest 1997)'s model, we have based it on previous ABMs research (Dal Forno and Merlone 2002, 2004) for the behavioural-outcomes box and on HRM empirical research for the relationship between boxes (Griffeth et al.|2000, Judge et al.|2001, Christen et al.2006). However, in order to design a model as simple as possible, neither the strategy box nor the financial box have been modelled and not all outcomes of the other boxes have been included in our agent-based model. 


\section{Attitudinal outcomes: Satisfaction}

1.7 Job satisfaction refers to how content an individual is in a job. It is measured within empirical studies either as an overall (global) feeling about the job, or as a sum of attitudes about various aspects of the job (facet approach) (Spector 1997). Facets of job satisfaction include rewards (such as pay or fringe benefits), relationship with other people (such as co-workers or supervisor), the nature of the work itself, personal growth, promotion opportunities, recognition, security and facilities, etc. In this paper, we follow the overall approach in order to model job satisfaction.

1.8 There seems to be a wide consensus among researchers that job satisfaction influences the intention to leave the organisation negatively and the employee's well-being positively (Griffeth et al.|2000).

\section{Behavioural outcomes: Effort}

1.9 Many empirical studies treat effort as part of job performance. This situation is probably due to the difficulties associated with defining and measuring effort. From a firm's perspective, effort and job performance may be difficult to distinguish, and effort is often inferred from job performance. From an employee's perspective, job performance and effort are different: effort is an input to work, and job performance is an output from this effort Christen et al.2006. Nevertheless, the ABM approach allows to distinguish them.

1.10 No consensus seems to be exist about the effort-satisfaction relationship. If effort is costly for an employee, from a theoretical argument, it should have a negative direct effect on job satisfaction. This implies that there is a conflict of interest between the employer (who wants the employee to work hard) and the employee (who wants the salary with the minimum possible effort) (Christen et al.2006). However, empirical studies that include effort as an antecedent tend to find that it has a positive effect on job satisfaction. Christen et al. (2006) solved this inconsistency between theoretical arguments and empirical findings. They found that effort has indirect positive effect on job satisfaction through the mediation of job performance and a direct positive effect on job performance. When the effect of job performance is eliminated from the job satisfaction equation, Christen et al. (2006) obtained a negative but insignificant negative effect of effort on job satisfaction, being consistent with the assumption that effort is costly to an agent. Therefore, we do not model a direct effort-satisfaction relationship.

1.11 In order to model effort we follow Dal Forno and Merlone 2002, 2004)'s ABM. Dal Forno and Merlone 2002, 2004) proposed a multi-agent simulation platform for modeling perfectly rational and bounded rational agents in organisations within an informal organisational structure in order to evaluate the emergence of culture (i.e., an equilibrium where all agents exert the same effort). In this paper, we consider some bounded rational agent considered by Dal Forno and Merlone (2002), but interacting within different formal organisational structures instead of an informal organisational structure.

\section{Organisational outcomes: Performance}

1.12 Performance refers to the degree of achievement of the mission at the work place that builds up an employee Cascio 2006). As multiple levels of performance analysis (e.g., individual, group, and organisational) are needed (Wright et al. 2003), ABM is especially suitable approach to understand the relationship between performance and the other boxes of Guest (1997)'s model by considering the variance across individuals.

1.13 Christen et al. 2006 obtained that job performance (i.e, performance at individual level) is determined by the employee's effort and ability. Therefore, we consider that effort has a direct positive effect on job performance, but not a direct effect on job satisfaction.

1.14 Nevertheless, the performance-satisfaction relationship is a controversial theme. By reviewing empirical research conducted in the 20th century, Judge et al. (2001) found at least seven different ways in which the performance-satisfaction relationship has been specified. Some of these models view the relationship between job satisfaction and job performance as unidirectional (i.e., either job satisfaction causes job performance or vice versa), some of these models view a false relationship or no-relationship, and others view a bidirectional relationship moderated by other variables (such as reward contingency, intrinsic job characteristics, self-esteem, organisational tenure, etc). In order to model job performance, we consider that job satisfaction causes job performance.

1.15 There seems to be a consensus among researchers that organisational performance (i.e, performance at organisational level) is determined by the HRM practices implemented by the organisation. In this paper, organisational performance emerges from the interactions between individuals within different organisational structures. 


\section{Organisational outcomes: Turnover}

1.16 Many models have been proposed to explain turnover since the original model by March and Simon (1958), where turnover is defined as "the departure of an employee from the formally defined organisation". Watrous et al. 2006 categorise turnover as voluntary or involuntary, as well as functional or dysfunctional.

1.17 Involuntary turnover, which is the process in which the organisation assumes the control over an employee's decision to leave or to stay (and decides to dismiss the employee), is often labeled as functional turnover because under-performing employees or those who do not fit within the organisational culture are removed and replaced by relatively higher performing new employees. Therefore, involuntary turnover would typically be associated with lower poor performing employees. Dal Forno and Merlone (2004)'s demonstrated that, in most situations, by firing under performance employees may increase overall employees' effort, but it is not guaranteed. In this paper, we follow Dal Forno and Merlone (2004)'s agent-based research in order to model involuntary turnover.

1.18 Voluntary turnover, which is the process in which an individual makes the decision to leave or to stay in the organisation (and decides to leave), is usually dysfunctional because it can be most detrimental to the organisation. Empirical evidence supports the dysfunctional effects in sense of being associated with decrements in organisational performance Hausknecht and Trevor 2011). Research typically focuses on the antecedents of the individual employee's decisions to leave, including employee demographics variables, job attitudes variables (such as job satisfaction and organisational commitment), and the ease of movement (see Griffeth et al. (2000) for a review of turnover research conducted in the 20th century). Alternative models have been proposed in order to better explain why people leave organisations (Lee et al. 1996) or why people stay in organisations Mitchell et al.2001). In this context, the term "employee retention", which refers to Human Resource Management (HRM) Practices implemented by companies to prevent valuable employees from leaving the organisation, began to appear as opposite side of the same coin (Holtom et al.2008). There is no previous agent-based research related to voluntary turnover.

\section{Organisational outcomes: A shared culture of effort}

1.19 Organisational culture typically is defined as a complex set of values, beliefs, assumptions and symbols that define the way in which a firm conducts its business (Barney 1986). In this paper, we focus on a shared culture of effort. It is not imposed by the organisation, but emerges from the interaction between employees. We consider that organisational culture emerges when all agents exert the same effort (Dal Forno et al. 2002). In strong organisational cultures, all employees exert the same level of effort to increase the overall organisational performance, whilst weak cultures may create diversity between the individual and organisational objectives.

1.20 The paper is organised as follows. In Section 2 the agent-based model is described. A detailed description of the model, using the ODD protocol proposed by Grimm et al. (2006), is available at http://www . eii.uva.es/ posada/HURLAB-0.html. In Section 3 the computational experiment settings and some results are reported. Discussion and concluding remarks are pointed out in Sections 4 and 5 .

\section{HURLAB: An Agent-Based Model}

2.1 HURLAB (HUman Resource LABoratory) is an agent-based model populated by two types of bounded-rational agents: organisation and employees (see Figure 2 for an overview of the model). In order to distinguish the level of performance analysis (individual, group, and organisational), the boxes of Guest (1997)'s model are redistributed according to the type of bounded-rational agent involved (organisation or employee). Lines and signs indicate the direction of effects, whereas indirect effects are represented by a dashed line.

2.2 The rates resulting from the decisions taken, either by the employees or by the organisation, are involuntary turnover (i.e., the percentage of employees who involuntarily leave the organisation) and voluntary turnover (i.e., the percentage of employees who voluntarily leave the organisation).

\section{The organisation}

2.3 The goal of the organisation is to achieve the maximum level of average performance with full occupation. Therefore, when an employee leaves the organisation (either voluntary or involuntarily) or retires, they are replaced by other one assuming some organisational replacement costs. 


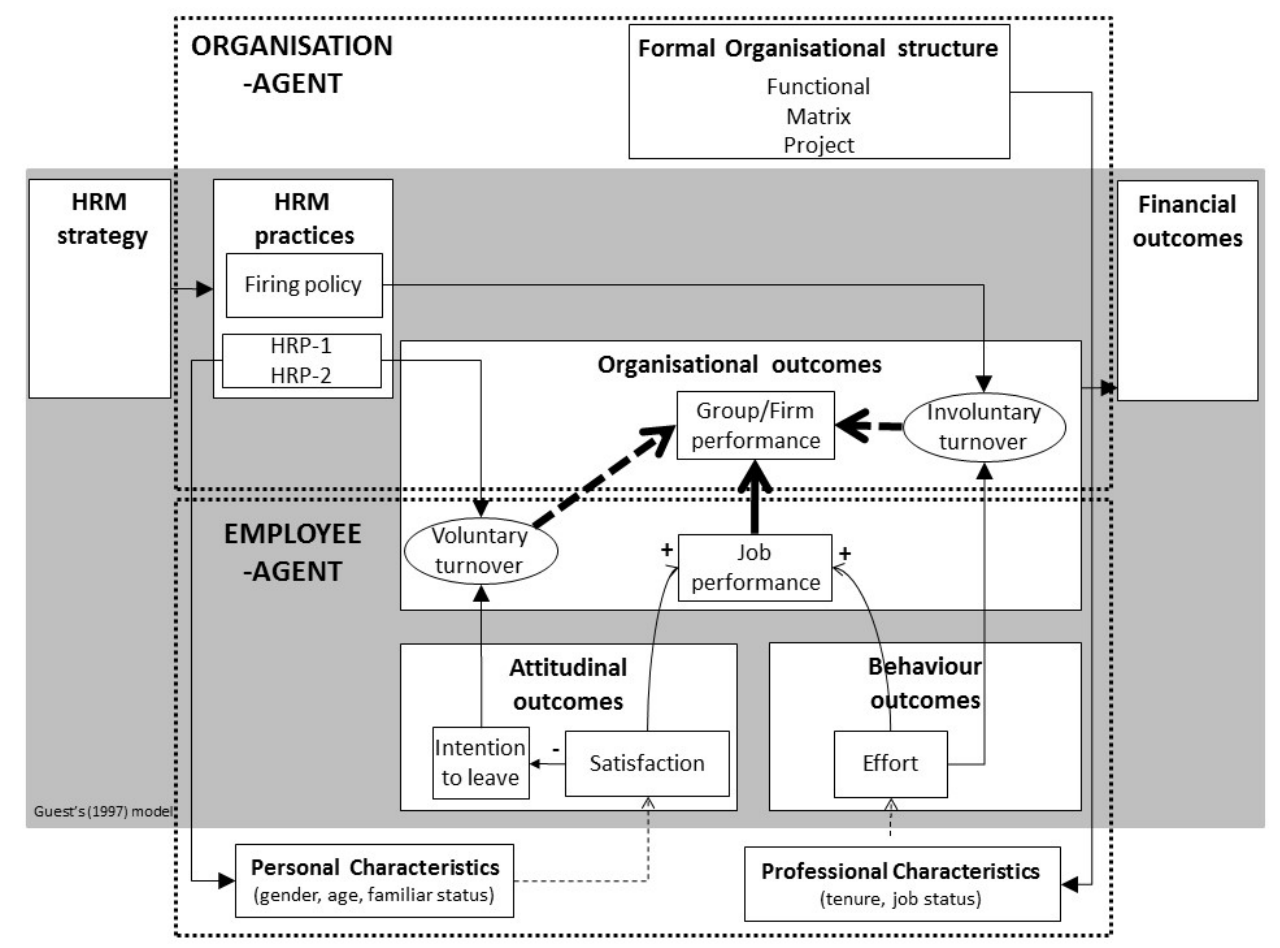

Figure 2: HURLAB-0 overview

\section{Variables}

2.4 The organisation is defined by the following variables: formal organisational structure (which includes the type of configuration and the description of the structure), team (such as team size, team leadership, number of projects per member and number of projects per project-manager), Human-Resource Management (HRM) Practices and outcomes (such as group performance and firm performance) (see Table 1 ).

2.5 Formal organisational structure: type configuration and levels. We define four levels from the general manager level (level4) to lowest level (level 0), which define the employee's job status, within the following configuration types: functional, balanced matrix, and strong matrix configurations. The interactions between the employees (represented by solid lines in Figure 3 will be determined by both the type of formal organisational structure and the type of team leadership.

2.6 Therefore, in a functional, balanced matrix and strong matrix configurations, department-managers report to (and interacts with) their general-manager, functional-managers report to (and interact with) their departmentmanager and area-managers report to (and interact with) their functional-manager. Workers of each area do not interact with the other workers of their own area due to only formal interactions are considered in this paper. Only in teams, workers interact between each other, but limited by both their role in the team and the team leadership.

2.7 In a balanced matrix and strong matrix configurations, workers are grouped into teams (represented by dashed lines in Figure 3. Individuals working in teams play one of the following two roles: project-manager (who coordinates the project and is represented by a black-person in Figure 3 or team-member. Project-managers report to (and interact with) their functional manager in balanced matrix, but to a multi-project-manager in strong matrix. They do not interact between each other. Team-members have to report to (and interact with) their functional manager as well as multiple project-managers (as many managers as projects each employee is involved into) in balanced and strong matrix.

2.8 Team leadership. Project-managers can exhibit a leadership behaviour between two extreme types: egocentered and democratic. In ego-centered leadership (represented by a star-shaped network), the projectmanager interacts with all team members, but members do not interact between each other. In democratic leadership (represented by a whole network), the project-manager and all team-members interact between each other.

2.9 Team size. Research on team size suggests a curvilinear relationship between team size and team effectiveness. Very small teams (i.e., 2 or 3 people) may lack diversity of perspectives, whereas larger teams (more than 10 

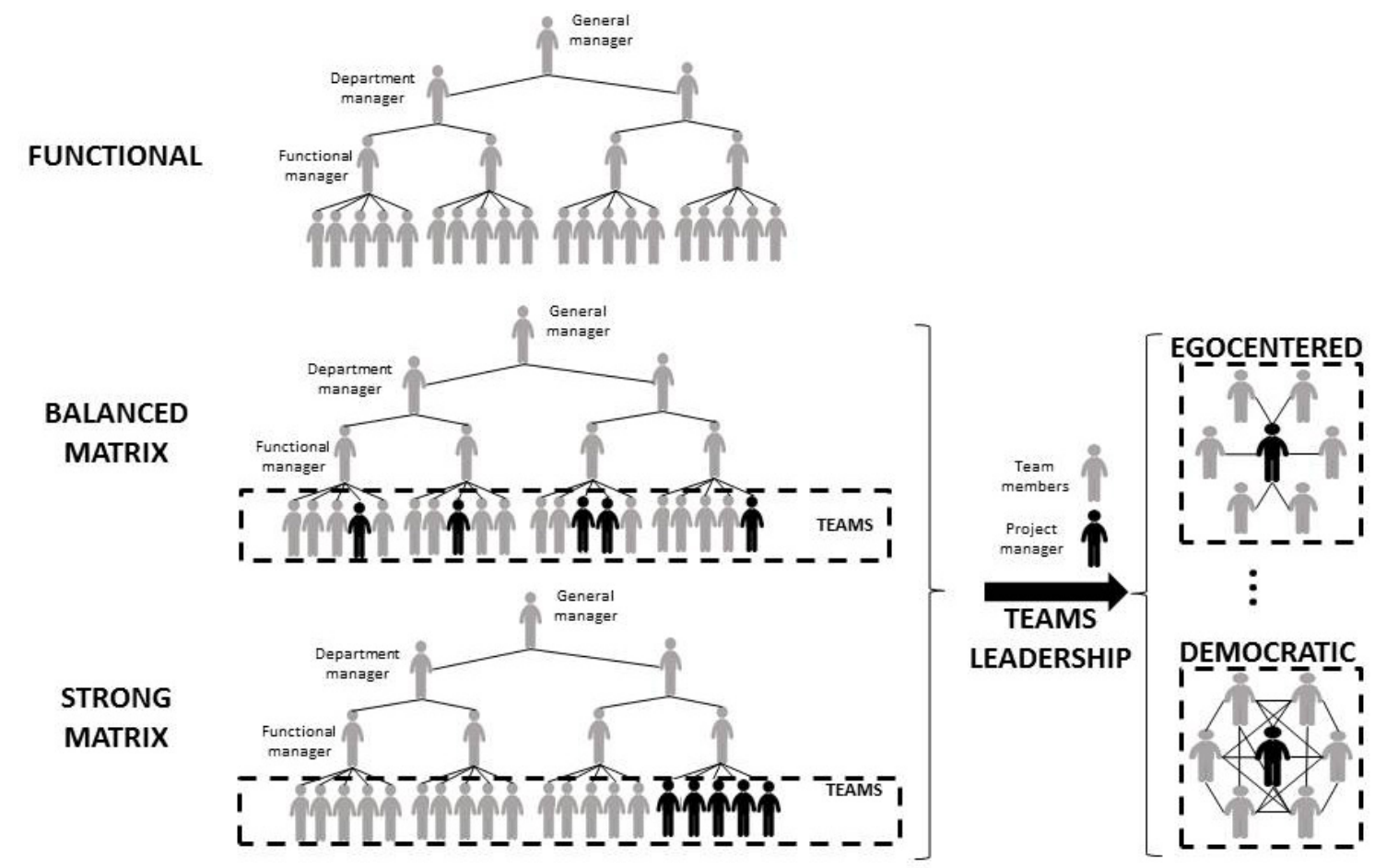

Figure 3: Formal organisational structures (functional, balanced matrix, and strong matrix) and team leadership (egocentered and democratic)

members) tend to divide into subteams, which hinders effective team interaction (Dionne et al.2010).

2.10 Human-Resource Management. The organisation dynamically interacts with employees by implementing a set of HRM practices. The following HRM practices can be considered: challenging job design, salary, promotion based on performance, initial-training, team-training, work-family balance programs, supervisor support, and schedule facilities. The effectiveness of the HRM practices implemented depends on the personal and professional goals of the employees.

2.11 Outcomes: firm performance and group performance. Firm performance is calculated as the average of individuals' job performance. Group performance is calculated as the average of individuals' job performance grouped either into a functional-area or into a team.

\section{Decisions}

2.12 In relation to involuntary turnover, the organisation dismisses employees whose effort is lower than a minimumeffort-to-stay level (called "firing-level" by Dal Forno et al.|2004), with the objective of achieving the maximum level of performance.

2.13 Besides, related to voluntary turnover, the organisation implements some HRM practices with the objective of both influencing the employees' satisfaction and retaining high-performing employees. This decision does not change over time.

\section{Employee-agents}

\section{Variables}

2.14 Employee-agents are defined by the following variables: their personal characteristics (such as gender, age and family status), professional characteristics (such as team role, tenure and job status), attitude and behaviour (such as effort and satisfaction) and outcomes (such as job performance and intention to leave) (see Table 2). In this paper, personal and professional characteristics are randomly initialised but, in order to be applied to real organisations, real data can be loaded. 
Table 1: Variables of the organisation-agent

\begin{tabular}{|l|l|l|}
\hline \multicolumn{2}{|c|}{ Parameter } & Parameter Value \\
\hline Formal organisational structure & Configuration type & $\begin{array}{l}\text { F-Functional, BM-balanced matrix, } \\
\text { SM-strong matrix }\end{array}$ \\
\cline { 2 - 3 } & Number of levels & $\begin{array}{l}\text { 4-highest level, 3-department supervisors, } \\
\text { 2-functional manager, 1-lowest level }\end{array}$ \\
\cline { 2 - 3 } & Number of departments & From 3 to 5 \\
\cline { 2 - 3 } & Number of areas per department & From 3 to 5 \\
\cline { 2 - 3 } & Number of employees per area & From 3 to 24 \\
\hline Team & Team leadership & E-Egocentered, D-Democratic \\
\cline { 2 - 3 } & Team size & From 3 to 10 \\
\cline { 2 - 3 } & Number of projects per member & From 1 to 3 \\
\cline { 2 - 3 } & Number of projects per & 1 \\
\hline Human- Resource-Management & Froject-manager & From 0 to 100 \\
\cline { 2 - 3 } & Firing level & Configurable list $\left(H R P_{1}, H R P_{2}\right.$ ) \\
\hline Outcomes & Group performance & Average individual performance (from 0 to 100) \\
\cline { 2 - 3 } & Firm performance & individual performance (from 0 to 100) \\
\hline
\end{tabular}

2.15 Employees dynamically interact both between each other and with the organisation, through a set of behavioural rules which determines the effort intensity (related to involuntary turnover) and the job satisfaction (related to voluntary turnover).

Table 2: Variables of an employee-agent

\begin{tabular}{|c|c|c|c|}
\hline \multicolumn{2}{|c|}{ Parameter } & Parameter Value & Update \\
\hline \multirow[t]{3}{*}{$\begin{array}{l}\text { Personal } \\
\text { characteristics }\end{array}$} & age & $\begin{array}{l}\text { From } 21 \text { to } 60 \text { years } \\
\text { (age groups: less than } \\
30,30-45,45-60, \text { more } \\
\text { than } 60 \text { ) }\end{array}$ & yearly \\
\hline & gender & 0-male, 1-female & No change \\
\hline & Family status & 0-has no family, 1-has a family & yearly \\
\hline \multirow{2}{*}{$\begin{array}{l}\text { Professional } \\
\text { characteristics }\end{array}$} & Job status & From level-0 to level-3 & Rule-based changes \\
\hline & Team role & 0-member, 1-project manager & Rule-based changes \\
\hline \multirow[t]{7}{*}{ Attitude and behaviour } & Effort & From 0 to 100 & Rule-based changes \\
\hline & Behaviour & $\begin{array}{l}\text { null, averager, replicator } \\
\text { high, comparator, shrinking }\end{array}$ & No change \\
\hline & Satisfaction & From -100 to 100 & Rule-based changes \\
\hline & Minimum-satisfaction-to-stay & From -100 to 100 & No change \\
\hline & $d_{s}$ & From 0 to 1 & No change \\
\hline & HRP weights $\left(s_{j}\right)$ & From 1 to 5 & Over the individual's life \\
\hline & $\mathrm{b}$ & From 1 to 2 & No change \\
\hline \multirow[t]{2}{*}{ Outcome } & Job performance & From 0 to 100 & Rule-based changes \\
\hline & Intention- to-leave & From 0 to 100 & Rule-based changes \\
\hline
\end{tabular}

2.16 Employee's effort. Employees differ in their effort intensity. Moreover, the effort exerted by each employee can vary in terms of intensity and persistence over their professional life, adapting their effort intensity by considering both their behaviour and their interactions with other employees.

2.17 We consider the following bounded-rational behaviours considered by Dal Forno and Merlone (2002), which were extrapolated from human-subject experiments, but the effort intensity ranges from 0 to 100 instead of 0 to 2: Null effort: this agent exerts always the same, almost null effort (between 0 and 10); Shrinking effort: this agent halves the effort provided by its last partner; Replicator: this agent exerts the same effort as its last partner exerted in the previous interaction; High effort: this agent exerts always the same high effort (between 81 and 100); Effort comparator: this agent compares its effort to its previous partner's effort; it increases its effort by $10 \%$ if it is lower than its partner's one and vice versa; Averager: it averages its effort with last partner's effort. The idea behind is that effort is contagion. 
2.18 With whom employees interact with, is defined by their position in the organisational configuration. Changes in effort intensity are observed by using a graded chromatic scale, which ranges from blue (low effort) to red (high effort).

2.19 Employee's satisfaction. The employee's satisfaction is estimated by assessing how much the HRM practices implemented by the organisation are aligned with their career goals and personal values. This feeling, which is private, changes over the employee's life and depends on both the personal characteristics (such as age, gender and family status) and the HRM practices implemented by the organisation. To measure it, we propose an endorsement scheme grounded on a methodology proposed by Cohen (1985) to reproduce heuristic reasoning:

$$
\operatorname{Satisfaction}(i)=\sum_{j} \tau(j) b^{s_{j}} / S_{\max }(i)
$$

where $j$ are the possible HRM Practices, $b$ is the employees' sensitivity to the organisation implements HRM practices and ranges from 1 (no sensitivity) to $2, s_{j}$ is the relevance of the $\mathrm{HRM}-j$ practice to the employee $-i$ and ranges on a 5-point Likert scale from 1 (not a priority) to 5 (essential), $\tau(j)$ is the implementation of the $\mathrm{HRM}-j$ practices by the organisation $(\tau(j)=1$ when the $\mathrm{HRM}-j$ practice is implemented and $\tau(j)=-1$ when it is not), and $S_{\max }(i)$ is the employee-i's satisfaction when all HRM practices valued by the employee are implemented by the organisation. In other words, employees sort in their minds a set of HRM practices into relevance order according to their personal characteristics. When one of these HRM practices is (is not) implemented by the organisation, employees have a satisfaction (dissatisfaction) feeling whose value depends on both $s_{j}$ and $b$.

2.20 For instance, when only two HRM practices can be implemented by the organisation, the following situations can take place: the organisation either implements $H R P-j$ or not (no- $H R P-j$ ), and the employee- $i$ considers the $H R P-j$ practice either important or not (see Table 3. Therefore, the satisfaction ranges from -100 (maximum dissatisfaction when the organisation does not implement any HRM practices which are important to each employee) to 100 (maximum satisfaction when the organisation implements all HRM practices which are important to each employee). When both HRM practices are important to an employee but only one is implemented by the organisation, the relative importance of the HRM practices for the employee $\left(s_{1}\right.$ versus $\left.s_{2}\right)$ determines the satisfaction value. This value is 0 when both HRM practices have the same importance for an employee. It is positive (i.e., the employee is satisfied but not completely) when the HRM practice which has been implemented is more important than the other one. It is negative (i.e., the employee is dissatisfied but not completely) when the HRM practice which has not been implemented is more important than the other one. Extending to more HRM practices is elementary.

Table 3: Satisfaction situations

\begin{tabular}{|l|c|cc|cc|}
\hline & & \multicolumn{2}{|c|}{ HRP-1 not-important } & \multicolumn{2}{|c|}{$\begin{array}{c}\text { HRP-1 important } \\
s_{1}=[1-5]\end{array}$} \\
\hline & & no-HRP-1 & HRP-1 & no-HRP-1 & HRP-1 \\
\hline HRP-2 not-important & no-HRP-2 & 0 & 0 & -100 & 100 \\
& HRP-2 & 0 & 0 & -100 & 100 \\
\hline HRP-2 important & no-HRP-2 & -100 & -100 & -100 & $\left(b^{s_{1}}-b^{s_{2}}\right) /\left(b^{s_{1}}+b^{s_{2}}\right)$ \\
$s_{2}=[1-5]$ & HRP-2 & 100 & 100 & $\left(-b^{s_{1}}+b^{s_{2}}\right) /\left(b^{s_{1}}+b^{s_{2}}\right)$ & 100 \\
\hline
\end{tabular}

2.21 The importance of the $H R P-j$ practice for the employee $\left(s_{j}\right)$ depends on employee gender (male/female), family status (family/no family) and age group (less than 30 years/30-45 years/45-60 years/more than 60 years)(see Table 4]. It changes over the employee's life depending on the employee's personal characteristics. Empirical studies on exploring the influence of gender (Griffeth et al.2000) found that women give preference to intrinsic values (for example, challenging job, development opportunities, and autonomy). In contrast, men significantly prefer extrinsic values (high earnings and job security). In order to this model be applied to a real organisation, a survey of employees can be conducted to assess how well possible HRM practices would fit with their career goals and personal values. The better they fit, the higher the likelihood of an employee feeling professionally and personally tied to the organisation.

2.22 How much the employee is satisfied, not only depends on the relative importance of the HRM practices for the employee $\left(s_{1}\right.$ and $\left.s_{2}\right)$ but also on the employees' sensitivity to the organisation implements HRM practices $(b)$. The effect of HRM practices implemented (or not) on job satisfaction is higher as the employees' sensitivity increases (see Figure 4). However, in certain vocational professions where $b$ could even be equal to 1, although 
Table 4: Relevance of HR Practices (F:family; NF:no-family

\begin{tabular}{|l|c|c|c|c|c|c|c|c|c|c|c|c|c|c|c|c|}
\hline years & \multicolumn{2}{|c|}{$<31$} & \multicolumn{2}{|c|}{$<1$} & \multicolumn{2}{|c|}{$31-45$} & \multicolumn{2}{|c|}{$31-45$} & $46-60$ & \multicolumn{2}{|c|}{$46-60$} & \multicolumn{2}{|c|}{+60} & \multicolumn{2}{|c|}{+60} \\
\hline gender & Male & Female & \multicolumn{2}{|c|}{ Male } & Female & \multicolumn{2}{|c|}{ Male } & \multicolumn{2}{|c|}{ Female } & \multicolumn{2}{|c|}{ Male } & \multicolumn{2}{|c|}{ Female } \\
\hline family status & NF & F & NF & F & NF & F & NF & F & NF & F & NF & F & NF & F & NF & F \\
\hline HRP-1 & & & & & & & & & & & & & & & & \\
\hline HRP-2 & & & & & & & & & & & & & & & & \\
\hline
\end{tabular}

HRM practices could be welcome and employees could have a sorted list in mind, they are not the reason of the satisfaction feeling.

2.23 Changes in satisfaction are observed by using a graded chromatic scale, which ranges from black (low satisfaction) to red (high satisfaction).
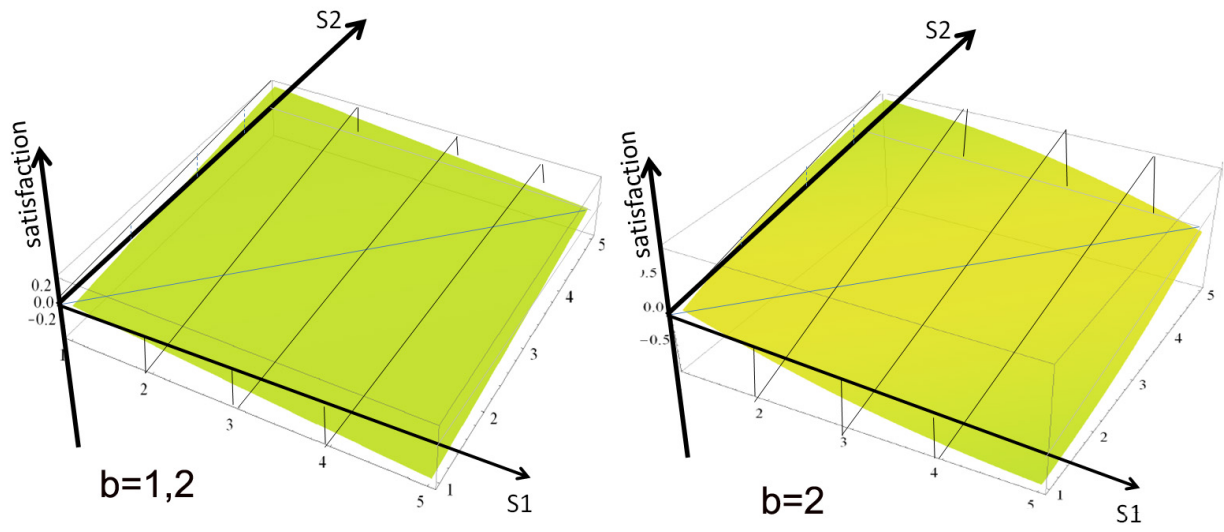

Figure 4: Satisfaction when only one HRM practice is implemented

2.24 Employee's intention to leave. Employees have the intention of leaving the organisation if their satisfaction is lower than a minimum-satisfaction-to-stay level.

2.25 Employee's job performance. Employees adapt their job-performance by considering both their effort and their satisfaction, as follows:

2.26

$$
\text { performance }=\text { effort }+d_{s} * \text { satisfaction, }
$$

where $d_{s}$ is the influence of satisfaction on job performance. It ranges from 0 to 1 . When $d_{s}=0$, the job performance is only influenced by effort. The influence of satisfaction on job performance is higher as $d_{s}$ increases. In order to simplify our model, we consider that this influence is the same for all employees. It is fixed at the beginning and does not change over the simulation.

2.27 Changes in the job performance are observed by using a graded chromatic scale, which ranges from blue (low performance) to red (high performance).

\section{Employee's decision}

2.28 We consider that the employees leave the organisation when they have the intention to leave.

\section{Simulations and Results}

3.1 We consider an organisation within a formal organisational structure whose lowest level is populated by 100 employees who are distributed into 5 functional areas (bellowing to 3 departments). The time of simulation 
ranges from 1 to 10 years. We have evaluated the following four scenarios. For each scenario, we have conducted some experiments on merging of different types of effort behaviour (null effort/shrinking/ comparator/replicator/averager), organisational formal structure (functional/balanced matrix/strong matrix) and team leadership (ego-centered/democratic). 30 repetitions per combination of parameters are considered to do the statistical analysis.

\section{Baseline scenario: The influence of formal organisational structures}

3.2 Parameters conditions: Homogeneous populations with different types of effort behaviours (null/high/shrinking /comparator/replicator/averager), $d s=0$ (i.e., job performance is only influenced by effort intensity), firing-level=0 (no involuntary turnover), minimum-satisfaction-to-stay=-100 (no voluntary turnover).

3.3 Our aim is to calibrate the effect of the organisational structure on the emergence of organisational cultures (i.e., an equilibrium where all agents exert the same effort) by comparing our results with Dal Forno and Merlone 2002)'s results where formal organisational structures were not created. The main result achieved is that matrix structures (balanced or strong) with a democratic team leadership can lead to the emergence of highperformance organisational cultures in homogeneous averager populations.

3.4 The evolution of the average effort in a run (for different types of effort behaviours within a functional formal organisational structure) are reported in Figure 5 . We observed that, in the last period, the average effort converges to 0 in homogeneous shrinking populations, whilst it converges to values lower than 50 in homogeneous comparator populations, fluctuates around 50 in homogeneous replicator populations and converges to 50 in homogeneous averager populations.

3.5 In order to evaluate if there is convergence to the same effort intensity in several repetitions within different formal organisational structures, the mean (and standard deviation) of the average effort achieved in the last period of 30 repetitions are reported in Table 5. We have obtained that:
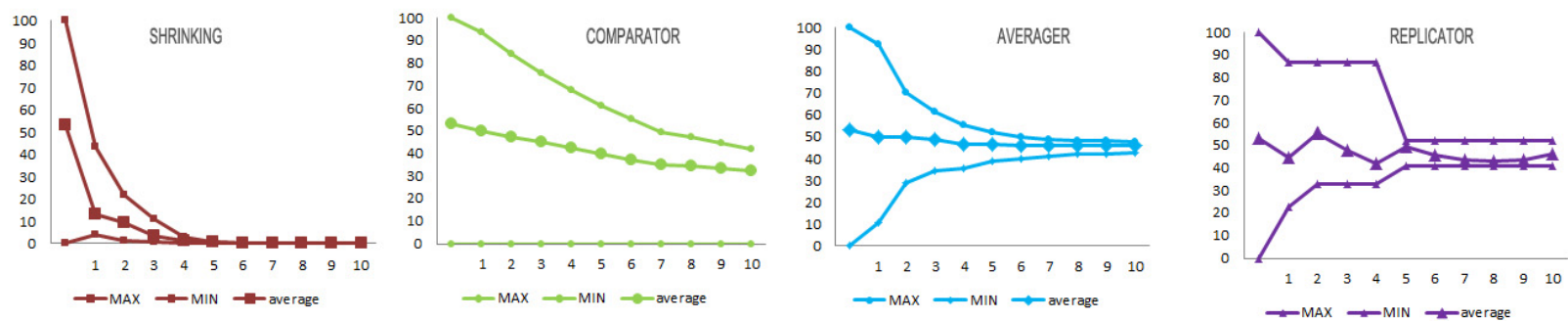

Figure 5: Evolution of the average effort in a run in homogeneous populations within a functional structure

Table 5: Mean and standard deviation of average effort in homogenous populations

\begin{tabular}{|l|c|c|c|c|c|}
\hline & Functional(F) & $\begin{array}{c}\text { Balanced (BE) } \\
\text { Egocentered }\end{array}$ & $\begin{array}{c}\text { Strong (SE) } \\
\text { Egocentered }\end{array}$ & $\begin{array}{c}\text { Balanced (BD) } \\
\text { Democratic }\end{array}$ & $\begin{array}{c}\text { Strong (SD) } \\
\text { Democratic }\end{array}$ \\
\hline Shrinking & 0,0049 & 0,0042 & 0,0040 & 0,0001 & 0,0000 \\
& $(0,0044)$ & $(0,0036)$ & $(0,0043)$ & $(0,0001)$ & $(0,0001)$ \\
\hline Comparator & 34,8752 & 34,6670 & 34,3201 & 30,0289 & 31,0774 \\
& $(6,0373)$ & $(6,7653)$ & $(6,6888)$ & $(6,6836)$ & $(7,8311)$ \\
\hline Averager & 48,7602 & 48,1754 & 47,4464 & 48,5784 & 47,6067 \\
& $(7,8264)$ & $(9,0858)$ & $(9,0320)$ & $(9,0840)$ & $(7,1876)$ \\
\hline Replicator & 45,7178 & 54,8138 & 48,6144 & 45,5985 & 51,0639 \\
& $(21,2365)$ & $(18,7548)$ & $(22,3808)$ & $(18,5623)$ & $(20,8931)$ \\
\hline
\end{tabular}

- For homogeneous shrinking populations, there is always convergence to an organisational culture where all the employees exert a null effort. Our results reproduce Dal Forno and Merlone (2002)'s results independently on the formal organisational structure. It can be observed in Table 5 that the average effort converges to 0 and the standard deviation is very low. This is visible in Figure 6 as an only blue-bar with frequency 100 . 
- For homogeneous replicator populations, there is no convergence to an organisational culture. Our results reproduce Dal Forno and Merlone (2002)'s results independently on the formal organisational structure. High standard deviations can be observed in Table 5 for all formal organisational structures. We have obtained a Pearson coefficient of variation which ranges from 0,34 (within a Balance-Egocentered structure) to 0,41 (with a Strong-Democratic organisational structure). This is reflected in Figure 6 by multicolour bars equally distributed. We have obtained the same conclusion by doing 100, 200 and 300 repetitions.

- For both homogeneous comparator and homogeneous averager populations, there is not a clear convergence to an overall organisational culture. We have obtained a Pearson coefficient of variation which ranges from 0,15 (for homogeneous comparator within a Strong-Democratic organisational structure) to 0,25 (for homogeneous averager populations with a Strong-Democratic organisational structure). We also observe green bars with frequency around 50 (see Figure 6. Therefore, there are reasons for a deeper analysis in order to evaluate either the emergence of subcultures associated to functional areas in one run or the emergence of cultures that, in different runs, converge to different effort intensities or not convergence as it happens in Dal Forno and Merlone 2002.

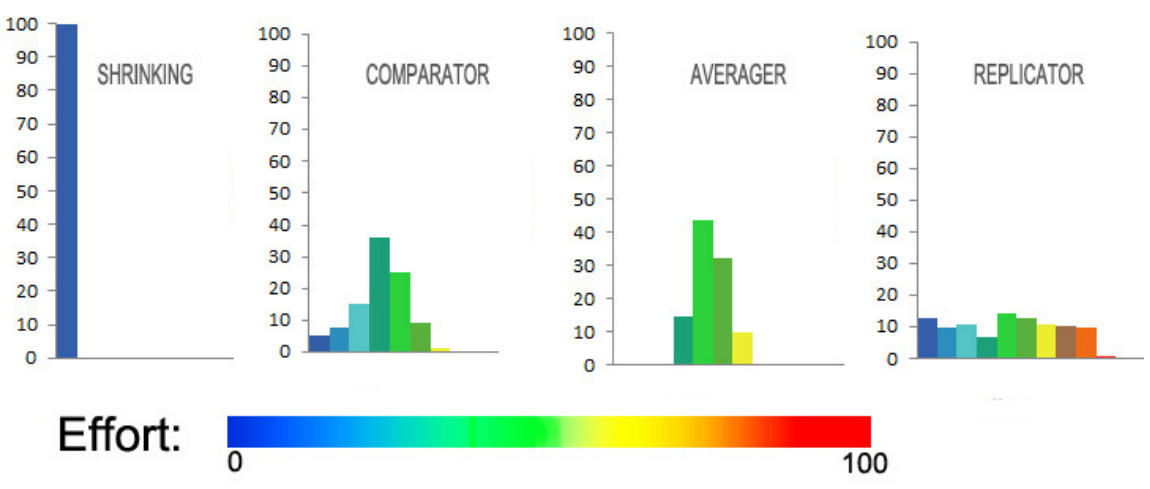

Figure 6: Mean of efforts distribution within a functional formal organisational structure

3.6 In order to evaluate the emergence of subcultures associated to functional areas, the mean in 30 repetitions of the standard deviations of the efforts exerted in the last period by the employees in each area (sd-area) in homogeneous-averager and homogeneous-comparator populations are reported in Table 6 and Table 7, respectively. In order to evaluate if these subcultures converge either to the same effort intensity or not, the standard deviation of the areas' average effort in the last period of 30 repetitions are reported in Table 6 and Table 7(last row). We have obtained that:

- For homogeneous averager populations, subcultures associated to each area emerge in all formal organisation structures as the mean of the standard deviations of the efforts by area are very low. But note that, in strong matrix structures with either ego-centered or democratic leadership (SE and SD), the highest mean of the standard deviations is achieved by area-5, which is the project-managers' area. Moreover, in democratic leadership in both matrix structures (BD and SD), subcultures converge to the same effort intensity as standard deviations between the means of the average effort by area is very low $(0,0222$ and 0,0207 , respectively). However, this effort intensity is not the same in all repetitions, that is the reason why the standard deviation of the average effort in 30 repetitions reported in Table 5 is high. We have also evaluated the influences of time size, obtaining that the effort distribution moves to higher effort intensities as the team size decreases (see Figure 7 .

- For homogeneous comparator populations, high standard deviation values can be observed in Table 5 in all formal organisational structures analysed. Therefore, there is no emergence of subcultures neither convergence to the same effort in a run.

\section{Heterogeneous scenario: The influence of high-performance employees}

3.7 Parameters conditions: Heterogeneous populations with different types of effort behaviours (high/shrinking/ comparator/replicator/averager), $d s=0$ (i.e., job performance is only influenced by effort intensity), firing-level $=0$ (no involuntary turnover), minimum-satisfaction-to-stay=-100 (no voluntary turnover). 


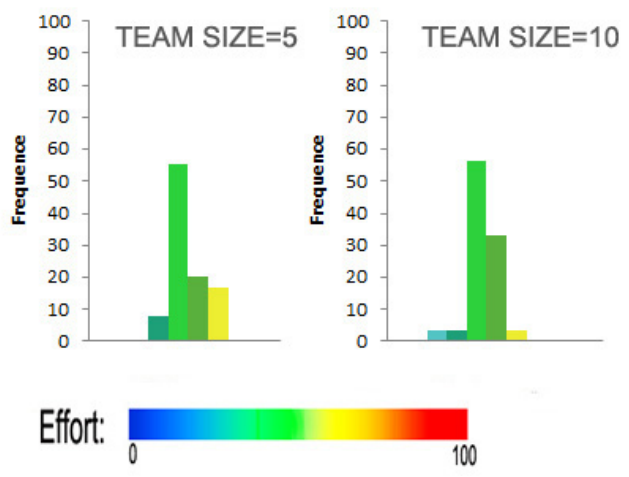

Figure 7: Team size influence on efforts distribution in homogenous averager populations within strongdemocratic organisational structure

Table 6: Efforts by areas in homogenous averager populations

\begin{tabular}{|l|c|c|c|c|c|}
\hline & Functional(F) & $\begin{array}{c}\text { Balanced (BE) } \\
\text { Ego-centered }\end{array}$ & $\begin{array}{c}\text { Strong (SE) } \\
\text { Ego-centered }\end{array}$ & $\begin{array}{c}\text { Balanced (BD) } \\
\text { Democratic }\end{array}$ & $\begin{array}{c}\text { Strong (SD) } \\
\text { Democratic }\end{array}$ \\
\hline sd-area 1 & 0,0843 & 0,1117 & 0,0287 & 0,03538 & 0,0216 \\
\hline sd-area 2 & 0,1438 & 0,0781 & 0,0283 & 0,02996 & 0,0228 \\
\hline sd-area 3 & 0,0919 & 0,1064 & 0,0269 & 0,03151 & 0,0214 \\
\hline sd-area 4 & 0,1652 & 0,1073 & 0,0278 & 0,03123 & 0,0207 \\
\hline sd-area 5 & 0,1828 & 0,1546 & 3,0114 & 0,03081 & 0,0317 \\
\hline mean-areas & $(3,0671)$ & $(2,9788)$ & $(2,5801)$ & $(0,0222)$ & $(0,0207)$ \\
\hline
\end{tabular}

3.8 Our aim is to calibrate the effect of high-effort employees within formal organisational structures on the emergence of organisational cultures by comparing our results with Dal Forno and Merlone (2002)'s results. The main result achieved is that, in heterogeneous populations, the presence of high-effort at management levels can lead to the emergence of organisational cultures.

3.9 Although Dal Forno and Merlone 2002 found difficulties to observe the emergence of organisational cultures in heterogeneous populations, they obtained that the average effort which results from introducing high-effort employees in homogeneous populations boosts the average effort. Moreover, its value depends on the proportion of high-effort employees introduced, except on null-effort populations where their influence is rather predictable (a linear combination of null-effort and high-effort, weighted by their relative proportions). Adapting Dal Forno and Merlone (2002)'s results to the range 0 to 100 (see Figure 8 -left), the average effort is 33,3 in $66,7 \%$ null-33,3\%high populations, around 50 in 66,7\%shrinking-33,3\%high populations, and 100 in both $66,7 \%$ averager-33,3\% high populations and 66,7\%comparator-33,3\%high populations.

3.10 Nevertheless, we have observed emergence of high-performance cultures when, in some heterogeneous populations within a formal organisational structure, high-effort individual work at supervisor-levels (i.e., areamanagers and department-supervisors). The percentage of high-effort employees needed for the emergence of organisational cultures drops to the percentage of supervisors ( $8 \%$ in our case: 100 employees at low-level and 9 at management-levels) (see Figure8-right).

Table 7: Effort by areas in homogenous comparator populations

\begin{tabular}{|l|c|c|c|c|c|}
\hline & Functional(F) & $\begin{array}{c}\text { Balanced (BE) } \\
\text { Ego-centered }\end{array}$ & $\begin{array}{c}\text { Strong (SE) } \\
\text { Ego-centered }\end{array}$ & $\begin{array}{c}\text { Balanced (BD) } \\
\text { Democratic }\end{array}$ & $\begin{array}{c}\text { Strong (SD) } \\
\text { Democratic }\end{array}$ \\
\hline sd-area 1 & 8,8297 & 8,4352 & 8,56733 & 3,2172 & 3,6157 \\
\hline sd-area 2 & 8,3943 & 8,3247 & 8,6570 & 3,4231 & 3,7499 \\
\hline sd-area 3 & 8,3278 & 7,8660 & 8,1397 & 2,9823 & 3,3488 \\
\hline sd-area 4 & 8,9733 & 8,3866 & 8,7310 & 3,2260 & 3,4640 \\
\hline sd-area 5 & 8,5498 & 7,9793 & 5,7858 & 3,6611 & 3,7765 \\
\hline mean-areas & $(7,5156)$ & $(7,0390)$ & $(7,0168)$ & $(0,91348)$ & $(1,02141)$ \\
\hline
\end{tabular}


3.11 We have obtained that organisational cultures emerge in heterogeneous populations when high-effort employees work at supervisor-levels in both replicator populations and averager populations within different types of formal organisational structures (see orange-red bars in Figure 99. In heterogeneous high-shrinking populations, two completely different subcultures emerge: high efforts associated to supervisor-levels, but low efforts associated to workers at low-level (see orange-red bars versus green bar in Figure 9. Organisational cultures do not emerge in high-comparator populations (see multi-colour bars in Figure9).

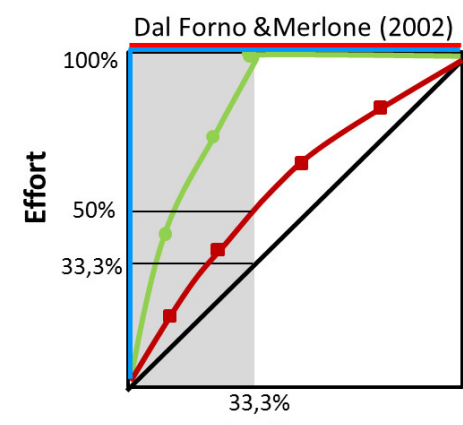

\% High effort agents

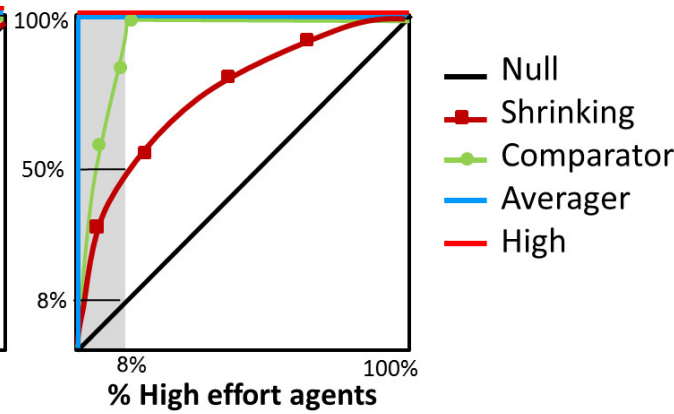

Figure 8: The influence of high-effort employees
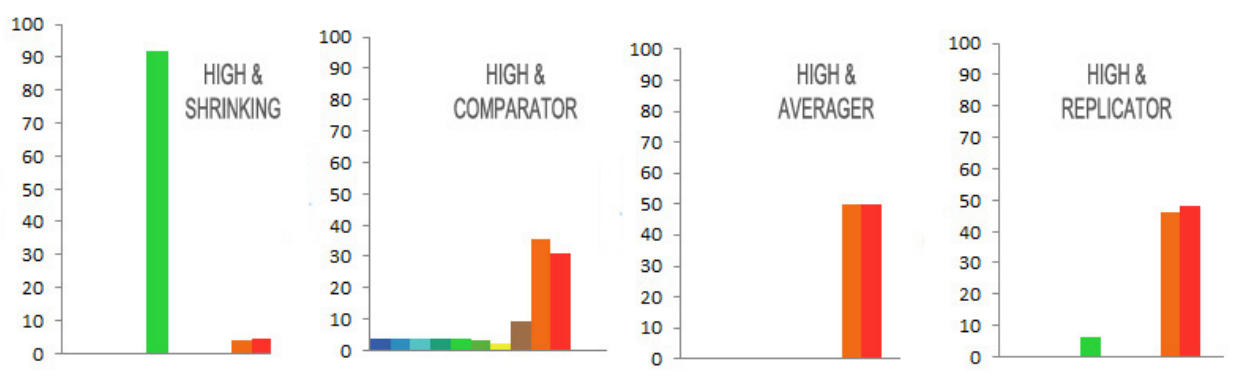

Effort:

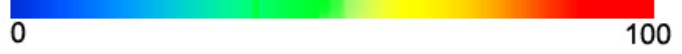

Figure 9: Mean effort distribution when high-effort employees are at supervisor level within a functional structure

Table 8: Mean and standard deviation of average effort in heterogeneous populations

\begin{tabular}{|l|c|c|c|c|c|}
\hline & Functional(F) & $\begin{array}{c}\text { Balanced (BE) } \\
\text { Ego-centered }\end{array}$ & $\begin{array}{c}\text { Strong (SE) } \\
\text { Ego-centered }\end{array}$ & $\begin{array}{c}\text { Balanced (BD) } \\
\text { Democratic }\end{array}$ & $\begin{array}{c}\text { Strong (SD) } \\
\text { Democratic }\end{array}$ \\
\hline \%Shrinking & 49,117 & 47,8881 & 47,6977 & 18,2671 & 17,0978 \\
\% High & $(0,8609)$ & $(1,2102)$ & $(1,3889)$ & $(5,3611)$ & $(4,9395)$ \\
\hline \% Comparator & 75,2233 & 76,1692 & 75,992 & 68,761 & 69,7737 \\
\% High & $(2,9734)$ & $(3,0789)$ & $(2,9785)$ & $(13,1787)$ & $(12,3855)$ \\
\hline \% Averager & 90,5991 & 90,0498 & 90,0234 & 90,4236 & 90,583 \\
\% High & $(1,7898)$ & $(1,841)$ & $(1,9918)$ & $(1,7111)$ & $(2,2138)$ \\
\hline \% Replicator & 90,6357 & 90,4767 & 90,3758 & 90,7742 & 90,671 \\
\% High & $(1,7922)$ & $(1,9808)$ & $(2,3867)$ & $(2,7443)$ & $(3,282)$ \\
\hline
\end{tabular}

\section{Involuntary turnover scenario: Dismissing low-effort employees}

3.12 Parameters conditions: Homogeneous populations with different types of effort behaviour (shrinking/comparator/replicator/averager), $d s=0$ (i.e., job performance is only influenced by effort intensity), firing-level ranges from 0 to 75 (i.e., there exists involuntary turnover), minimum-satisfaction-to-stay=-100 (no voluntary turnover). 
3.13 Our aim is to analyse both the entry of new workers and the departure of low-effort employees. The main result achieved is that involuntary turnover affects the emergence of organisational cultures negatively.

3.14 The departure of low-employees increases as the firing-level increases. Therefore, involuntary turnover increases (except in homogeneous shrinking populations where the involuntary turnover rate is always near 100 $\%)$. The departure of low-effort employees and the entry of new workers lead to opposing effects on the emergence of organisational cultures.

3.15 On the one hand, dismissing low-performance employees leads to high average effort organisational cultures. In Figure 10 the evolution of the average effort in a run for different types of effort behaviours (within a functional structure) are reported. In homogeneous shrinking populations, the average effort in the last period ranges from 10 to 25 , in homogeneous comparator populations from 30 to 70 , and in homogeneous averager populations from 45 to 70 . We observe that the average effort is higher as the firing-level increases, but when the firing-level is too high the opposite effect appears. The mean (and standard deviation) of the average effort achieved in the last period of 30 repetitions within two extreme types of formal organisational structures (functional and Strong-Democratic) are reported in Table 9 in order to compare a firing-level $=25$ with the baseline scenario's results (see Table 5 , first and last columns).

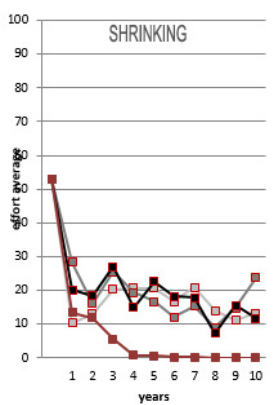

years

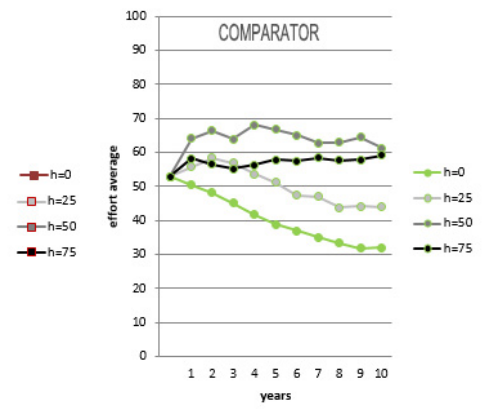

years
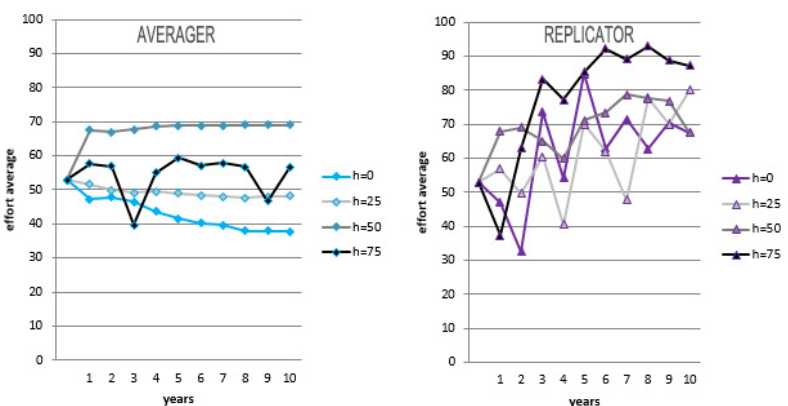

years

Figure 10: Evolution of the average effort in a run in homogeneous populations within functional structure and different firing-levels

Table 9: Mean and standard deviation of average effort in homogenous populations with firing-level=25

\begin{tabular}{|l|c|c|}
\hline & Functional(F) & $\begin{array}{c}\text { Strong (SD) } \\
\text { Democratic }\end{array}$ \\
\hline Shrinking & $\begin{array}{c}14,9360 \\
(4,1615)\end{array}$ & $\begin{array}{c}3,7735 \\
(1,9899)\end{array}$ \\
\hline Comparator & 53,3930 & 47,4457 \\
& $(6,3130)$ & $(6,0921)$ \\
\hline Averager & 59,3909 & 57,8952 \\
& $(7,6642)$ & $(7,2537)$ \\
\hline Replicator & 63,9238 & 63,3100 \\
& $(15,6934)$ & $(15,1119)$ \\
\hline
\end{tabular}

3.16 On the other hand, the entry of new employees whose efforts are not aligned with their co-workers' effort, both reduces the emergence of organisational cultures causing variations in the convergence patterns to an effort intensity. We observe in Figure 10 these variations either between periods (in textitshrinking and textitreplicator populations) or for high firing-levels (in comparator and averager populations). The weight of these variations depends on both the type of effort behaviour and the firing-level. In Table 10 , both the mean of standard deviation of efforts by each area and the standard deviation of the areas' average effort are reported for homogeneous averager populations within strong-democratic organisational structure for different firing-levels $(25,50$ and 75). We observe that they increase as firing-level increases (by comparing the results obtained for different firing-levels (Table 10] with the Baseline scenario results (Table 6ls last row)). We had the temptation of removing these variations between periods by selecting only workers whose efforts were higher than the firing-level. We discarded it because, however, real organisations select their employees by estimating their ability, but not their effort. 
Table 10: Efforts by areas in homogenous averager populations within strong-democratic organisational structure for different firing-levels

\begin{tabular}{|l|c|c|c|}
\hline Firing-level & 25 & 50 & 75 \\
\hline Voluntary turnover & $3 \%$ & $13 \%$ & $97 \%$ \\
\hline sd-area 1 & 0,2124 & 0,0442 & 4,2365 \\
\hline sd-area 2 & 0,2339 & 0,0445 & 4,3644 \\
\hline sd-area 3 & 0,2099 & 0,0489 & 4,2890 \\
\hline sd-area 4 & 0,2914 & 0,0462 & 4,1391 \\
\hline sd-area 5 & 0,2362 & 0,0497 & 4,5349 \\
\hline mean-areas & $(0,1438)$ & $(0,0370)$ & $(3,5073)$ \\
\hline
\end{tabular}

\section{Turnover scenario: Retaining high-performance employees}

3.17 Parameters conditions: Homogeneous populations of different types of effort behaviours (shrinking/comparator/replicator/averager), $d s$ ranges from 0,1 to 1 (i.e., job performance is influenced by both effort intensity and job satisfaction), firing-level=25 (there exists involuntary turnover), minimum-satisfaction-to-stay from -100 to 0 (there exists voluntary turnover).

3.18 Our aim is to analyse the effect of turnover on both the performance and the emergence of organisational cultures by comparing them with the previous scenarios results. Turnover-scenario is more realistic as the employees can leave the organisation voluntarily (if they decide to do it) or involuntarily (if the organisation decides to dismiss them) as it happens in real life. The main result we have achieved is that implementing HRM practices which prevent valuable employees from leaving the organisation, favours high-performance organisations.

3.19 Job satisfaction affects both performance and voluntary turnover. When the organisation implements both HRM practices and the employee valued at least one of these HRM practices, job satisfaction is $100 \%$ independently on both how much each HRM practice is valued by the employee (from 1 to 5 ) and how sensitive the employee is to their implementation by the organisation (from 1,1 to 2). Therefore, there is no voluntary turnover. Due to this relationship at individual level is rather simple, we expected the same relationship at organisational level, as it occurs. Figure 11 shows the effort-performance relationship for homogeneous populations within a functional organisational structure. Job performance increases as $d s$ increases. When $d s=0$, job performance is equal to effort (see Table 9 for a firing-level=25).

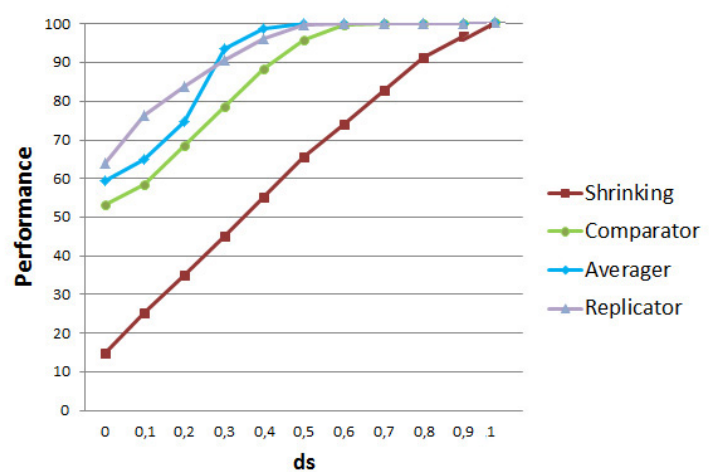

Figure 11: Effort-performance relationship in homogeneous average population within a functional structure and firing-level $=25$

3.20 When only one HRM practice is implemented by the organisation, job satisfaction depends on how much the employee values each HRM practice. In order to evaluate the effect of retaining high-performance on both the performance and the emergence of organisational cultures, we consider the following situation: an organisation implements HRP-1 practice which is rather popular for all group ages $\left(s_{1}=3\right)$, but high-effort individuals (between 30 and 45 years, with children) who are at the management level valued so much the implementation of work/family programmes $\left(s_{2}=5\right)$ (see Table 11). Therefore, only high-effort individuals between 30 and 45 years leave the organisation. What are the consequences of implementing HRP-1 practices decision? By comparing the results reported in Table 12 with involuntary scenario (see Table 9 and taking into account the 
effort-performance relationship, we conclude that implementing HRP-1 practice reduces the emergence of a high-performance organisational culture due to both lower means and higher standard deviations than in involuntary turnover scenario are obtained.

3.21 However, what would be the consequences of implementing HRP-2 practice instead of the popular HRP-1 practice? By comparing the results reported in Table 13 with involuntary scenario (see Table 9 and taking into account that the effort-performance relationship, we conclude that implementing HRP-2 practice affects the emergence of high-performance organisational cultures positively due to both higher means and lower standard deviations than in involuntary turnover scenario are obtained. Nevertheless, turnover scenario affects the emergence of organisational cultures negatively due to higher standard deviations are achieved by comparing with the second scenario (see Table 8 .

Table 11: Relevance of HR Practices

\begin{tabular}{|l|c|c|c|c|c|c|c|c|c|c|c|c|c|c|c|c|}
\hline years & \multicolumn{2}{|c|}{$<31$} & \multicolumn{2}{|c|}{$<31$} & \multicolumn{2}{|c|}{$31-45$} & \multicolumn{2}{|c|}{$31-45$} & \multicolumn{2}{|c|}{$46-60$} & \multicolumn{2}{|c|}{$46-60$} & \multicolumn{2}{|c|}{+60} & \multicolumn{2}{|c|}{+60} \\
\hline gender & \multicolumn{2}{|c|}{ Male } & \multicolumn{2}{|c|}{ Female } & \multicolumn{2}{|c|}{ Male } & \multicolumn{2}{|c|}{ Female } & \multicolumn{2}{|c|}{ Male } & \multicolumn{2}{|c|}{ Female } & \multicolumn{2}{|c|}{ Male } & \multicolumn{2}{|c|}{ Female } \\
\hline family status & NF & F & NF & F & NF & F & NF & F & NF & F & NF & F & NF & F & NF & F \\
\hline HRP-1 & 3 & 3 & 3 & 3 & 3 & 1 & 3 & 1 & 3 & 3 & 3 & 3 & 3 & 3 & 3 & 3 \\
\hline HRP-2 & 1 & 1 & 1 & 1 & 1 & 5 & 1 & 5 & 1 & 1 & 1 & 1 & 1 & 1 & 1 & 1 \\
\hline
\end{tabular}

Table 12: Mean and standard deviation of average performance for implementing HRP-1 practice in heterogeneous high-average populations with firing-level $=25$

\begin{tabular}{|l|c|c|}
\hline & Functional(F) & $\begin{array}{c}\text { Strong (SD) } \\
\text { Democratic }\end{array}$ \\
\hline Shrinking & 19,3706 & 9,923 \\
& $(3,7736)$ & $(1,9871)$ \\
\hline Comparator & 57,3542 & 50,8221 \\
& $(6,4383)$ & $(6,3205)$ \\
\hline Averager & 56,7434 & 60,6494 \\
& $(8,5761)$ & $(8,3596)$ \\
\hline Replicator & 69,6006 & 70,3876 \\
& $(15,8269)$ & $(17,8909)$ \\
\hline
\end{tabular}

Table 13: Mean and standard deviation of average performance for implementing HRP-2 practice in heterogeneous high-average populations with firing-level $=25$

\begin{tabular}{|l|c|c|}
\hline & Functional(F) & $\begin{array}{c}\text { Strong (SD) } \\
\text { Democratic }\end{array}$ \\
\hline Shrinking & 39,5704 & 15,541 \\
& $(3,1461)$ & $(4,4026)$ \\
\hline Comparator & 69,7471 & 55,4505 \\
& $(2,5837)$ & $(6,7033)$ \\
\hline Averager & 78,0347 & 77,3244 \\
& $(4,7365)$ & $(5,1081)$ \\
\hline Replicator & 83,9237 & 82,9103 \\
& $(5,8864)$ & $(8,8652)$ \\
\hline
\end{tabular}

\section{Discussion}

4.1 This model was motivated by the need for progress on explaining how Human Resource Management theory and theory on performance are linked. An examination of the literature suggests that effort, satisfaction, performance, turnover and organisational culture are relevant, but many studies fail to account for multi-level 
phenomena of these variables relationships. The model we propose incorporates these variables that are relevant in empirical studies. They were modeled at individual level according to empirical studies (Griffeth et al. 2000, Judge et al. 2001, Christen et al. 2006. Emergent phenomena from the interactions of individuals were observed at organisational level.

4.2 Effort. The model we propose includes some bounded-rational behaviours considered by Dal Forno and Merlone (2002), which were extrapolated from human-subject experiments: high-effort, low-effort, shrinking, averager, replicator, and comparator. These behaviours can be considered more or less realistic according to real life, but the idea behind is: "the effort exerted is contagious". Although this intuitive idea could be familiar to practitioners, to date there has been little information available about another person's effects on performance depending on what that other person is doing (Desender et al. (2016) addressed this issue).

4.3 Effort-organisational structure-organisational culture. We have obtained that both some effort behaviours exerted by the employees and some formal organisational structures can favour the emergence of organisational cultures: homogeneous shrinking populations, homogeneous averager populations, or even homogeneous replicator populations within an appropriate formal organisational structure, but never homogeneous comparator populations.

4.4 In homogeneous shrinking populations, low-performance organisational cultures emerge. However, organisations are interested in high-performance organisational cultures. Some formal organisational configuration could favour the emergence of high-performance organisational cultures. In particular, we have obtained that high-performance organisational cultures and sub-cultures emerge in homogeneous averager populations within matrix structures (balanced or strong) with a democratic team leadership. The emergence of highperformance organisational cultures is also favoured when high-effort employees at management levels (i.e., functional-areas and department-supervisors) interacts with any of types of employees' effort behaviours (shrinking, averager, replicator, and even comparator).

4.5 Schein 1992 advanced the idea that organisations can have subcultures linked to a different management team, either co-existing or conflicting. In our paper, we have achieved that subcultures are associated to some types of effort behaviours. Co-existing subcultures are associated to both functional areas and some types of effort behaviours. Nevertheless, conflicting subcultures are associated to both organisational levels and conflicting effort behaviours.

4.6 Performance-turnover-organisational culture. Turnover (voluntary or involuntary) affects the emergence of organisational cultures negatively. Therefore, in order to promote high-performance organisational cultures, the main challenge is to retain high-effort managers. This challenge can be faced by adapting the set of HRM practices to those valued by these high-employees, moreover taking into account the costs associated to turnover. Boushey and Glynn (2012), by reviewing 30 case studies taken from the 11 most-relevant research papers on the costs of employee turnover, demonstrated that it costs businesses about one-fifth of a worker's salary to replace that worker. They found that average costs to replace an employee are $6 \%$ of annual salary for high-turnover low-paying jobs (earning under $\$ 30,000$ a year), $20 \%$ of annual salary for mid-range positions (earning $\$ 30,000$ to $\$ 50,000$ a year) and up to $213 \%$ of annual salary for highly educated executive positions. Although, in order to make a decision, this economic valuation is crucial, it has been omitted in our model.

4.7 Understanding both the degree to which high-performance HRM practices affect organisational performance and the conditions that moderate this relationship, helps researchers to build contingencies in theory and aids practitioners to justify investments in HRM practices (Combs et al. 2006).

\section{Summary and Further Research}

5.1 This article attempts to show an alternative approach to understand the link between Human Resource Management theory and theory on performance. The HURLAB-0 is a simulation platform which provides a simple way to study the complex interactions between different types of agents interacting within different types of formal organisational configurations in organisations with different set of HRM practices.

5.2 We have obtained that: (i) Some possible combinations of both employees-effort behaviours and formal organisational structures can favour the emergence of organisational cultures more than others; (ii) The interaction between employees within matrix structures (balanced or strong) with a democratic team leadership favour the emergence of organisational cultures; (iii) High-effort managers are relevant for the emergence of highperformance organisational cultures; (iv) Turnover (voluntary or involuntary) affects the emergence of organisational culture negatively. We conclude that the main challenge is "to retain high effort managers by adapting the set of HRM practices to them". 
5.3 The most obvious extension is the validation of our model. Windrum et al. (2007) reviewed three of the most influential approaches to empirical validation that have been developed in the agent-based literature. The history-friendly approach constrains parameters, interactions, and decision rules in the model in line with the specific, empirically-observable history of a particular industry. The other two approaches employ empirical evidence to identify sub-regions in the potential parameter space and, within these sub-regions, the model is expected to replicate some relevant statistical regularities or stylised facts.

5.4 Nevertheless, none of these approaches can be used to validate our agent-based model because it has been already designed employing empirical evidence. Therefore, we cannot use the same empirical evidence to validate it. The only way to validate our model is to apply it to real life, in a particular organisation. However, in order to do it, our model has to be extended including the following issues: costs associated to turnover Boushey et al.2012, national cultural differences Hofstede et al.2001, and a more complex effort-satisfactionperformance relationship (Judge et al.2001). All these works are in process.

5.5 Finally, although we are aware that our model could be rather simple by comparing with real life, we believe that our simulation platform could be of interest to researchers (inspiring empirical studies) and practitioners (allowing to test Human Resource Management decisions both without consequences and before being implemented in a real organisation by characterizing the employees in a virtual environment).

\section{Acknowledgements}

We would like to thank to both 11th Artificial Economics conference's and JASSS's referees for their useful comments.

\section{References}

Boushey, H. and Glynn, S.J. (2012). There Are Significant Business Costs to Replacing Employees. Center for American Progress.

Barney, J. B. (1986). Organizational culture: Can it be a source of sustained competitive advantage?. Academy of Management Review, 11(3), 656-665.

Cascio, W. F. (2006). Managing Human Resources: Productivity, Quality of Life, Profits. New York, NY: McGraw-Hill Irwin.

Cohen, P. R. (1985). Heuristic Reasoning: An Artificial Intelligence Approach. Boston: Pitman Advanced Publishing Program.

Combs, J., Liu, Y., Hall, A. and Ketchen, D. (2006). How much do high-performance work practices matter? A meta-analysis of their effects on organizational performance. Personnel Psychology 59(3), 501-528.

Christen, M., Iyer, G. and Soberman, D. (2006). Job satisfaction, job performance, and effort: A reexamination using agency theory. Journal of Marketing, 70(1), 137-150.

Dal Forno, A. and Merlone, U. (2002). A multi-agent simulation platform for modeling perfectly rational and bounded-rational agents in organizations. Journal of Artificial Societies and Social Simulation, 5(2), 1460-7425.

Dal Forno, A. and Merlone, U. (2004). Personnel turnover in organizations: An agent-based simulation model. Nonlinear Dynamics, Psychology, and Life Sciences, 8(2), 205-230.

Desender, K., Beurms, S., and Van den Bussche, E. (2016). Is mental effort exertion contagious?. Psychonomic Bulletin and Review, 23(2),624-631.

Dionne, S. D. , Sayama, H., Hao, C. and Bush B.J. (2010). The role of leadership in shared mental model convergence and team performance improvement: An agent-based computational model. The Leadership Quarterly, 21, 1035-1049.

Dow, G. K. (1988). Configurational and coactivational views of organizational structure. Academy of Management Review, 13(1), 53-64. 
Dyer, L. and Reeves, T.(1995). HR strategies and firm performance: What do we know and where do we need to go. International Journal of Human Resource Management, 6, 656-670.

Galbraith, J. R. (2008). Designing Matrix Organizations that Actually Work: How IBM, Procter \& Gamble and Others Design for Success. Hoboken, NJ: Jossey-Bass.

Gilbert, G. N. (2008). Agent-Based Models. London: Sage.

Griffeth, R. W., Hom, P. W., Gaertnert, S. (2000). A meta-analysis of antecedents and correlates of employee turnover: Update, moderator tests, and research implications for the next millennium. Journal of Management, 26(3), 463-488.

Grimm, V., Berger, U., Bastiansen, F., Eliassen, S., Ginot, V., Giske, J., Goss-Custard, J., Grand, T., Heinz, S. K., Huse, G., Huth, A., Jepsen, J. U., Jørgensen, C., Mooij, W. M., Müller, B., Pe'er, G., Piou, C., Railsback, S. F., Robbins, A. M., Robbins, M. M., Rossmanith, E., Rüger, N., Strand, E., Souissi, S., Stillman, R. A., Vabø, R., Visser, U. and DeAngelis, D. L. (2006). A standard protocol for describing individual-based and agent-based models. Ecological Modelling, 198(1-2), 115-126.

Guest, D. E. (1997). Human resource management and performance: A review and research agenda. International Journal of Human Resource Management, 8, 263-276.

Hausknecht, J. P. and Trevor, C. O. (2011). Collective turnover at the group, unit, and organizational levels: Evidence, issues, and implications. Journal of Management, 37, 352-388.

Holtom, B. C., Mitchell, T.R., Lee, T. W. and Eberly, M. (2008). Turnover and retention research: A glance at the past, a closer review of the present, and a venture into the future. Academy of Management Annals, 2, 231-274.

Hofstede, G., Hofstede G.J. and Minkov, M. (2010). Cultures and Organizations: Software of the Mind. 3rd Edition. New York, NY: McGraw-Hill.

Judge, A. T., Iyer, G. and Soberman, D. (2001). The job satisfaction - job performance relationship: A qualitative and quantitative review. Psychological Bulletin, 127(3), 376-407.

Lee, T., Mitchell, T., Wise, L. and Fireman, S.: An unfolding model of voluntary employee turnover. Academy of Management Journal, 39, 5-36.

March, J. and Simon, H. A. (1958). Organizations. New York, NY: Wiley.

Mitchell, T. R., Holtom, B. C., Lee, T. W., Sablynski, C. J., Erez, M. (2001). Why people stay: Using job embeddedness to predict voluntary turnover. Academy of Management Journal, 44, 1102-1121.

Paauwe, J. and Boselie, P. (2005). HRM and performance: What next?. Human Resource Management Journal, 15(4), 68-83.

Salas, E., Sims, D. E. and Burke, C. S.: Is there a "Big Five" in teamwork?. Small Group Research, 36(5), 555-599.

Shahzad, F., Luqman, R. A., Khan, A. R. and Shabbir, L. (2012). Impact of organizational culture on organizational performance: An overview. Interdisciplinary Journal of Contemporary Research in Business, 3(9), 975-985.

Schein, E. (1992). Organizational Culture and Leadership: A Dynamic View. San Francisco, CA: Jossey-Bass.

Secchi, D. and Neumann, M. (2015). A case for agent-based model in organizational behavior. Team Perfomance Management, 21(1-2), 37-50.

Spector, P. (1997). Job Satisfaction: Application, Assessment, Causes and Consequences. London: Sage.

Watrous, K. M., Huffman, A. H. and Pritchard, R. D. (2006). When coworkers and managers quit: The effects of turnover and shared values on performance. Journal of Business and Psychology, 21, 103-126.

Windrum, P., Fagiolo, G. and Moneta, A. (2007). Empirical validation of agent-based models: Alternatives and Prospects. Journal of Artificial Societies and Social Simulation, 10(2), 8.

Wright, P. M. and Gardner, T. M. (2003). Theoretical and empirical challenges in studying the HR practice-firm performance relationship. In D. Holman, T. D. Wall, C. Clegg, P. Sparrow and H. Howard (Eds.), The New Workplace: People, Technology, and Organisation. Chichester: Wiley.

Wright, P. M. and Haggerty, J. J. (2005). Missing variables in theories of strategic human resource management: Time, cause, and individuals. Management Review, 16(2), 164-173. 